\section{SJESR}

Sir Syed Journal of Education \& Social Research

\title{
Role of Breast Cancer Awareness Advertising Educational Messages in Educating Women to Develop a Precautionary Behavior
}

\author{
*Moneeba Iftikhar: PhD scholar (CMCS), University of Gujrat \\ **Dr. Fakhra Aziz: Assistant Professor, Lahore College for Women University \\ ***Dr. Zahid Yousaf: Associate Professor and Chairperson (CMCS), University of Gujrat
}

\begin{abstract}
Breast cancer is a burning female health related issue and constantly increasing the threat for women around the globe. This study intends to analyze the power of an educational intervention in form of educational message on television to educate Pakistani women in order to improve their attitudes in adoption of precautionary behavior. The effects of these educational communication strategies are recorded by using the quantitative survey technique and a close ended questionnaire was distributed among the female respondents. A total of 300 women of Lahore Pakistan aged 20-40 were selected. Breast cancer awareness advertising educational message have been disseminated on television by Shaukat Khannum Cancer Hospital have been watched by respondents every year on television are intended to make women aware about the early diagnosis and the results reveal that these educational campaigns are not significantly educating women to develop a precautionary behavior in order to self-examine or tend them toward precautionary measures. Women are aware of breast cancer issues but still not clear about self-examination and consequences of delay in diagnosis of this fatal disease.
\end{abstract}

Key Words: Breast Cancer, Educational Messages, Precautionary Behavior, Women

\section{Introduction}

The human body consists of trillions of living cells. Cancer starts when cell starts to grow out of control in a part of the body. There are different types of cancer but all starts because of excessive growth of unusual cells. Cancer cell growth varies from normal cell growth in the body. Cancer cells can also expand into other tissues (Avis, 2005). Breast cancer is the most diagnosed cancer in both advanced and under-developed states. Breast cancer in Karachi,

\footnotetext{
*Lecturer, Department of Mass Communication, Lahore College for Women University, Lahore

Email: moneeba.iftikhar@1cwu.edu.pk

** (Corresponding Author) Assistant Professor, Editor JASS \& IJEER; Lahore College for Women University

Email: fakhra.aziz@lcwu.edu.pk

***Centre of Media and Communication Studies University of Gujrat, Email: zahid.yousaf@uog.edu.pk
} 
Pakistan is 69.1 per 100,000 with breast cancer existence in last stages 3 and 4 (Ahmed, 2006). In Pakistan, the most familiar cancer diagnosed is breast cancer. Approximately one in nine women lost their lives because of breast cancer. Pakistan is 2.5 times higher than that in closest countries like Iran \& India (Asif, 2014).

Many people are not aware of the importance of health, that's why there are many diseases common among them. Health communication campaigns target to change attitude or aware people about certain disease. Corporations of Ministry of health and NGOs launch those campaigns and make efforts to make people conscious and persuasive about health and diseases (Iftekhar, 2002).

The concept of 'healthy lifestyle' is dominant force in precaution of disease and health promotion advertisements. It is considered an important element in the adoption of both 'health impairing habits' and 'health protective behaviors'. Different state organizations and health associations have sought to aware and persuade people to adopt health practices or to ignore behaviors that create a risk to health. Under their public service messages, the broadcast media have allocated free slots for health Public Service Educational Messages, some TV channels have felt the responsibility to provide free space for these message (Aktin, 2001).

Breast cancer cases have been increased both in advanced and under-developed countries evenly. Survival percentages of breast cancer are higher in advanced states because of availability of improved services of timely detection and surgery. According to their study, death rates of breast cancer are directly related with the phase of the disease at detection time that is, 5 years survival is approximated at $80-90 \%$ with phase-I detection and is decreased to $22-63 \%$ with phase-II detection. A woman cannot expire of breast cancer if it is diagnosed at early phase before becoming incursive. The study stresses on breast cancer awareness and breast self-examination (BSE) as sources for initial diagnosis of breast cancer in advancing states. Every year death of 40,000 women are reported due to breast cancer. At SKMCH Memorial Cancer Hospital \& Research Centre Lahore (SKMCH \& RC) breast cancer is still the extreme malignancy reported and presently being treated over the years. Breast cancer causes are not recognized yet and study into this continues. However, researches have shown that early diagnosis of breast cancer can lead to survival rate of over $90 \%$. The aim of this research to examine application of BSE which can be done by the women themselves. No 
professional expertise or visit to the hospital which involves specific instruments is required. Regular practice of BSE can lead to the early diagnosis of breast cancer. It expands the chances for early surgery and as a result the survival rate in women.

Mr. Sohaib Sharif manager product development in marketing section of SKMCH Cancer Memorial Hospital \& Research Centre (7-5-2019) stated that SKMCH starts breast cancer advertising educational campaign in the month of October which continues till November. This awareness campaign includes different activities such as awareness sessions in institutes, public service messages on TV, social media campaigns, seminars, pink tea parties at offices and homes, distribution of broachers, billboard, awareness walks, Polo in Pink etc. The purpose of this campaign is to produce awareness about the breast cancer. It aware people about the symptoms and precaution regarding breast cancer. It also helps people in clarifying their questions regarding breast cancer. SKMCH mostly use social media as it major tool for awareness as it is not too much costly. There are 3.5 million followers on Facebook page of SKMCH.

Celebrities also play very important role in these awareness campaigns as they represent the campaign as ambassadors. It helps to grab the attention of audience in more effective way. The most recent ambassadors of breast cancer awareness campaign are Mahira Khan, Sanam Saeed and Maya Ali.

SKMCH Memorial Cancer Hospital \& Research Center (SKMCH) that every year many women die because there is no pattern of mass detection in Pakistan. Unfortunately, largely poor women are expiring of breast cancer. Furthermore, many women do not talk about their health problems with others and are shy to try any sort of breast examination, due to lack of awareness. Not only aged women, it is impacting younger also. In Pakistan, hundreds of women expire due to breast cancer every year. Obesity, overweight and aversion of breastfeeding are the main reasons of breast cancer among women. In Pakistan, one in nine women is diagnosed with breast cancer at some point of their lives.

The aim of the research is to keenly and enthusiastically examine the attitude and knowledge of women regarding the disease conveyed through SKMCH Breast Cancer advertising educational campaign. The researcher wants to know the effectiveness of this awareness campaign and whether the women examine under the age of 40 and over the age of 40 get annual mammography screening. 
The aim of that research is to check the impact of SKMCH Breast Cancer advertising educational campaigns. Furthermore, to explore the behavior and understanding regarding breast cancer (symptoms and prevention) among women of Lahore created through SKMCH breast cancer advertising educational campaign to make them healthy women of society.

The aim and purpose of the research are:

- To know whether women are aware about the disease and practicing breast selfexamination concept

- To find out behavior and attitudes of women and their families towards breast cancer awareness campaign

- To study the change in the behavior of women to take precautionary measures after receiving the breast cancer awareness educational messages.

\section{Literature Review}

Public service awareness educational messages are informative short movies made with the objective to increase the awareness and create behavioral changes (İnci, Sancar \& Bostanci, 2017). Health messages are used to change the attitudes of people, in these messages target particular audiences. Public service awareness educational create awareness among people and instructs the public about health (Georgiasis, 2013).

Public service awareness educational messages are non-commercial advertisements that try to change behaviors of people and attitudes by highlighting consciousness about certain issues (Klimes, Dougan \& Lee, 2010). In past years, Public service awareness educational messages have been started to broadcast on Internet as another advertising media (Walther, DeAndrea, Kim \& Anthony, 2010). Public service awareness educational messages are very significant in educating, creating awareness, motivating, and informing various groups for social issues, if they are produced rightly and highlighted on proper media platforms (Toncar, Reid \& Anderson, 2007). Effective health messages in the public service awareness educational messages have to change in people, and also change people viewpoint about their health issues. Through public service awareness educational messages show them benefits of suggested actions. They often use fear appeals for prompting behaviors and intention change (Keys, Morant \& Stroman, 2009). Media have positive effect on health related problems, beliefs, attitude and behaviors when it is used properly (Zimmerman et al., 2007). Public service awareness educational messages that use internet, videos, television 
spots, brochures and posters are one of the most typical components of the social marketing campaigns. The objective of public service awareness educational messages range from awareness to behavior change (Reichert, Heckler \& Jackson, 2001). Public service awareness educational messages should present knowledge in ways that are informative, attractive, new, useful and encouraging (Grow \& Christopher, 2008). The pervasiveness of advertising makes it seem strong and useful for health promotion (Wallack \& Dorfman 1993).

The purpose of the Glynn (2011)'s research was to analyze the search activity regarding breast cancer. The effects on the search activity were studied in the month of breast cancer awareness. The comparison of breast cancer campaigns with lungs and prostate cancer awareness campaigns was studied in breast cancer awareness month. According to the results the online activity regarding breast cancer noticeably increased. So, it was concluded that the breast cancer awareness campaign is verifying effective and encouraging online search activity on breast cancer.

Pezzullo (2003) conducted a research and result shows that since 1984, the month of October is recognized in the U.S as National Breast Cancer Awareness Month. National Breast Cancer awareness month has increased general understanding of breast cancer is "Stop Cancer Where It Starts".

Amirali (2014) conducted a research and results shows that Breast cancer is the second most popular cause of causalities among Pakistani females. The lack of medical services, limited female are unaware amongst people in rural areas of Pakistan are the main problems that need to be addressed to settle the problem timely. According to their research the beginning of this twenty first century, more than one million women were detected with breast cancer out of which 373,000 died in the year 2000 and 519,000 women died in the year 2004 worldwide.

Banning(2013) conducted a research and result shows that the cultural importance of detection of advanced breast cancer is important in Pakistan especially due to the high rate in women, limited breast cancer screening, healthcare plans and cancer awareness programs in Pakistan. Therefore, the mental effect of breast cancer is an important consideration for women. In this qualitative research examined the mental effect of advanced breast cancer in Pakistani women. According to their research, twenty-one advanced breast cancer women were interviewed. Women agreed feelings regarding the insecurity of health, battle to cancer, 
the effect of their disease on their physical and emotional health and marital relationships and emotions related to cultural distinction.

Masood (2018) conducted a research and result shows that the trends and patterns of most common male and female cancers from 1984-2014 for the city population of Lahore Pakistan. Cancer incidence data gathered for different organs were processed through cleaning, integration, transformation, reduction and mining for ultimate representation. Risk of cancer appeared to be continuously increasing among both males and females. Overall, lymphomas and breast cancer are the most popular neoplasm in males and females, respectively, in Lahore with almost the highest rates in the Asian Pacific region. The frequency of head and neck, brain and lung cancers, as well as leukemia have rapidly increased among males, whereas, ovarian, cervix, head and neck and lymphomas have become more common among females. The present communication should be helpful for adequate strategic planning, identification of risk factors and taking appropriate prevention and control measures at the national level.

Amin (2011) conducted a research and result shows that the present situation of breast cancer in Pakistan, with its increasing rate and mortality, expensiveness and inaccessibility to screening, detection and surgery, Patel Hospital took up the task to address these problems at community level and began an annual free breast camp in the year 2006. In 2008 an addition method was designed to focus on high risk women for breast cancer. According to their research a relative study over three years period was done. Total 11 patients were detected to have cancer after analysis. Six patients underwent specific surgery. The aim of this study is to analyze an issue with lack of awareness, regarding screening and cure protocols was recognized. Family background is a significant risk element in our set up signifying the need to introduce huge screening programs.

Thackeray (2013) conducted a research and the result shows that every one out of eight women will develop breast cancer in her life. The best-known recognition event is breast cancer awareness month (BCAM). The aim of this study was to perceive how Twitter is being used during BCAM. Tweeting about breast cancer was a single incident. Most of tweets did not encourage any particular prohibitive attitude. Twitter is mostly being used as a one-way communication tool. According to their study the administrations may consider 
combining with individuals and celebrities in these discussions. Social media communication techniques highlight the fundraising for breast cancer survivals.

\section{Theoretical Framework}

The study has analyzed "Role of Breast Cancer Awareness Advertising Educational Messages in Educating Women to Develop a Precautionary Behavior". The prime purpose of this study was to find out the behavior of women regarding the awareness of SKMCH breast cancer advertising campaigns and their practices to protect them from the disease.

\section{The Selective Exposure Study}

Selective exposure theory is an idea in media and communication study that mentions to individual's inclination to advocate knowledge that strengthens pre-existing viewpoints while avoiding opposed knowledge. In this study individuals incline to select particular features of revealed information based on their viewpoint, beliefs behaviors and resolutions. Selective exposure is a theory within the application of psychology, frequently used in media and communication study that historically means individuals' inclination to advocate knowledge which strengthens their pre-existing views while avoiding which opposed knowledge. Cautious revelation has also been known and termed as "congeniality bias" or "confirmation bias" in different texts all over the years. Attitude construct predicts modification elsewhere that is foreseen.

The idea of critical revelation depends on the premise that knowledge seeking attitude continues even after a person has taken a posture on a problem. Former information-pursuing attitude will be colored by different aspects of the problem that is operated during the decision making method. Therefore, selective exposure sets off by strengthening faiths rather than revealing individuals' autonomy. There are many elements that induce one while making decisions. This concept explain that media messages that is presented to the member of mass society is experienced and perceived particularly, the ground of this particularity lies in contrasts in habits of consideration among members of society. The effects of media breast cancer advertising campaigns are not uniform and powerful equally. This is a fact that media is playing a significant role in educating and informing people and certain media campaigns are participating in creating awareness among the women of Pakistan regarding Breast Cancer but the content that is presented for information do not affect all the target audience (women) equally in fact all the women do not practice the Breast Self-Examination procedure 
and precautionary measures to save themselves from the disease while some take it seriously in true meanings. Hence, the researcher found this concept of selective influence for research.

\section{Hypothesis}

$\mathbf{H}_{\mathbf{1}}$ : Breast cancer advertising educational campaigns are significantly motivating women to develop a precautionary behavior

$\mathbf{H}_{2}$ : Breast cancer advertising educational campaigns are not significantly developing a precautionary behavior towards Breast Cancer

\section{Research Methodology}

Survey has been selected by the researcher to make the research accurate and reliable. The main purpose of this research technique is to get the satisfactory results regarding the specific issue. The researcher has used survey method to analyze (SKMCH) breast cancer advertising educational campaign in motivating the women to develop a precautionary behavior towards breast cancer.

According to the nature of the research, the quantitative method that is survey has been applied in this study to collect the data. Survey method is applied to get the required information by conducting survey, gathering information about the large number of women. The aim of selecting the survey method was to regulate the influence of the breast cancer advertising educational campaign by SKMCH motivating the women to develop a precautionary behavior towards breast Cancer. Questionnaire for survey was developed by the researcher keeping in mind specific context and is validated by experts in the area. They also found it reliable.

\section{Data Analysis}

An analysis of variance (one way ANOVA) was conducted to explore the behavior and attitude of women after watching SKMCH breast cancer advertising educational campaigns in motivating the women to develop a precautionary behavior towards breast cancer.

Q No.1 Are you a health conscious person? 
Table 1: Health conscious person

\begin{tabular}{lccccc}
\hline & $\begin{array}{c}\text { Sum of } \\
\text { Squares }\end{array}$ & df & Mean Square & F & Sig. \\
\hline Between Group & 93.678 & 22 & 4.258 & 6.818 & .000 \\
Within Groups & 173.002 & 277 & .625 & & \\
Total & 266.680 & 299 & & & \\
\hline
\end{tabular}

Q No. 2 Do you have any information regarding cancer?

Table 2: Cancer awareness

\begin{tabular}{lccccc}
\hline & $\begin{array}{c}\text { Sum of } \\
\text { Squares }\end{array}$ & df & Mean Square & F & Sig. \\
\hline Between Group & 91.293 & 22 & 4.150 & 8.931 & .000 \\
Within Groups & 128.707 & 277 & .465 & & \\
Total & 220.000 & 299 & & & \\
\hline
\end{tabular}

Q No. 3 Do you have any information regarding Breast Cancer?

Table3: Breast cancer awareness

\begin{tabular}{lccccc}
\hline & $\begin{array}{c}\text { Sum of } \\
\text { Squares }\end{array}$ & df & Mean Square & F & Sig. \\
\hline Between Group & 142.921 & 22 & 6.496 & 17.803 & .000 \\
Within Groups & 101.079 & 277 & .365 & & \\
Total & 244.000 & 299 & & & \\
\hline
\end{tabular}

Q No. 4 What is the main source of getting information regarding Breast Cancer?

Table 4: Main source of awareness

\begin{tabular}{lccccc}
\hline & $\begin{array}{c}\text { Sum of } \\
\text { Squares }\end{array}$ & df & Mean Square & F & Sig. \\
\hline Between Group & 155.840 & 22 & 7.084 & 12.756 & .000 \\
Within Groups & 153.827 & 277 & .555 & & \\
Total & 309.667 & 299 & & & \\
\hline
\end{tabular}

Q No. 5 Do you have any knowledge about Breast Cancer related advertising campaign by SKMCH that are launched in Pakistan every year? 
Table 5: Awareness of Breast Cancer related advertising campaign

\begin{tabular}{lccccc}
\hline & $\begin{array}{c}\text { Sum of } \\
\text { Squares }\end{array}$ & Df & Mean Square & F & Sig. \\
\hline Between Group & 185.451 & 22 & 8.430 & 19.210 & .000 \\
Within Groups & 121.549 & 277 & .439 & & \\
Total & 307.000 & 299 & & & \\
\hline
\end{tabular}

Q No. 6 Which source is more effective for creating awareness regarding Breast Cancer?

Table 6: More effective for creating awareness regarding Breast Cancer

\begin{tabular}{lccccc}
\hline & $\begin{array}{c}\text { Sum of } \\
\text { Squares }\end{array}$ & df & Mean Square & F & Sig. \\
\hline Between Group & 105.931 & 22 & 4.815 & 6.540 & .000 \\
Within Groups & 203.949 & 277 & .736 & & \\
Total & 309.880 & 299 & & & \\
\hline
\end{tabular}

Q No. 7 Have you seen any Breast Cancer (symptoms, preventions etc) related public service messages on television?

Table 7: Breast Cancer related public service messages on TV

\begin{tabular}{lclccc}
\hline & $\begin{array}{c}\text { Sum of } \\
\text { Squares }\end{array}$ & df & Mean Square & F & Sig. \\
\hline Between Group & 190.540 & 22 & 8.661 & 17.121 & .000 \\
Within Groups & 140.127 & 277 & .506 & & \\
Total & 330.667 & 299 & & & \\
\hline
\end{tabular}

Q No. 8 Does Public Service Advertising provides effective information to the audience/women regarding Breast Cancer?

Table 8: Effectiveness of Public Service Advertising

\begin{tabular}{lccccc}
\hline & $\begin{array}{c}\text { Sum of } \\
\text { Squares }\end{array}$ & Df & Mean Square & F & Sig. \\
\hline Between Group & 114.840 & 22 & 5.220 & 13.252 & .000 \\
Within Groups & 109.107 & 277 & .394 & & \\
Total & 223.947 & 299 & & & \\
\hline
\end{tabular}


Q No. 9 Have you watched any Breast Cancer awareness advertising campaign of SKMCH \& $\mathrm{RC}$ ?

Table 9: Observation of any Breast Cancer awareness advertising campaign of SKMCH \& RC

\begin{tabular}{lclccc}
\hline & $\begin{array}{c}\text { Sum of } \\
\text { Squares }\end{array}$ & df & Mean Square & F & Sig. \\
\hline Between Group & 205.062 & 22 & 9.321 & 16.169 & .000 \\
Within Groups & 159.685 & 277 & .576 & & \\
Total & 364.747 & 299 & & & \\
\hline
\end{tabular}

The significance has been found between the independent variable and dependent variable. For this $\mathrm{H} 1$ is accepted that SKMCH breast cancer advertising educational campaigns are significantly motivating women to develop a precautionary behavior.

\section{Discussion}

According to this research mostly women are health conscious, only few women are not health conscious. Many women have information regarding cancer. Women have information regarding breast cancer are very likely. TV, Radio, Posters, Pamphlets and seminars are the main source of getting information towards breast cancer. Women of Lahore have likely knowledge about breast cancer related advertising educational campaigns by SKMCH launched every year in Pakistan. TV is more effective source for creating awareness regarding breast cancer.

Mostly women have watched breast cancer related public service messages on television. Women strongly agree that public service advertising provide effective information regarding Breast Cancer. Many women of Lahore are very likely watching breast cancer awareness advertising educational campaigns of SKMCH Memorial Cancer Hospital and Research Center (SKMCH\&RC).SKMCH advertising educational campaign is very likely successful in motivating the women to develop a precautionary behavior towards breast cancer. According to this research women have likely knowledge regarding breast selfexamination procedure. These public service awareness advertising campaigns motivated women likely breast self-examination.

In this study women visited consultant not likely after getting information regarding breast cancer. Mostly women likely share the breast cancer related information with friends and close ones. Many of the women do not share that information because of fear, hesitation 
and embracement. After getting this research the results show that neutral behavior of families motivate the breast checkup from the consultant after getting information regarding breast cancer after watching public service advertising educational campaign by SKMCH. In this study women are very likely psychologically scared after getting information regarding breast cancer. These public service awareness advertising campaigns regarding breast cancer create sentiments like panic, anxiety and hope.

The finding of this study shows that the majority of women have knowledge about the advertising educational campaigns of breast cancer. Many women know about these advertising campaigns. According to women, media which includes TV, radio, brochures and pamphlets are the main source of getting information regarding breast cancer, while few women shows they actually get the information from seminars that they attended in universities.

Most of the women have knowledge about the SKMCH breast cancer advertising educational campaigns that are launched every year in Pakistan for creating attentiveness regarding the disease, few women mentioned that very likely they are aware about the campaigns, while small group of women cleared that they are not at all aware about the campaigns. However, only very few women explained that perhaps they are aware but not confirm at all.

As far as the exposure of the disease is concerned majority of women have seen and listened public service awareness messages regarding the breast cancer on TV. According to the opinion of women, electronic media which include TV and radio are more effective and convenient sources for creating awareness regarding breast cancer. Some shows that seminars are more influencing source, on the other hand some showed print media such as pamphlets $\&$ brushers are effective way similarly only very few women expressed their opinion in the favor of other sources. Many women are considered aware about the Breast Self-Examination (BSE) procedure that is practiced to make the breast safe from this fatal disease. These Educational messages are likely playing an effective role to make the women aware about the threats of the Breast Cancer.

\section{Conclusion}

Overall the research showed that majority of women has information regarding the breast cancer. Due to this public service advertising by SKMCH launched in Pakistan every year. 
The researcher has also explored the attitudes and behavior of women and their families regarding breast cancer precautionary behavior have been tried to find out. According to SKMCH, advertising educational campaign is very likely successful in motivating the women to develop a precautionary behavior towards breast cancer. According to this research women have likely knowledge regarding breast self-examination procedure. These public service advertising educational campaigns motivated women likely breast selfexamination. Because Advertising messages have power to shape and develop women thoughts to take decisions (Iftikhar \& Islam 2017). In this research women were not interested to visit consultant after getting information regarding breast cancer. Mostly women partially share the breast cancer related information with friends and close ones. Many of the women do not share that information because of fear, hesitation and embracement. These findings also support the theoretical framework of this research. According to the topic researcher apply selective exposure theory which proves that media do not have uniform impact on all target audiences people normally have different thinking styles some become serious towards the public service advertising educational messages while some remain neutral toward the issue just like research find out that some women take the breast cancer advertising campaigns so seriously in the form of sharing information with the family and close ones while some on the other hand remain neutral in this respect. As a Nicotera point out that behavior is not designed rather it is constructed by the environment around people.

In the light of all findings it is observed that breast cancer advertising educational campaigns in motivating the women to develop a precautionary behavior towards breast cancer that are launched every year in Pakistan is successful and should be continued in future. The research find out that these SKMCH breast cancer advertising educational campaigns should not be timely but frequent to make the information more clear to the audiences through it positive results can be easily found because the key aim is to save the women from this fatal disease for further concern.

\section{References}

Ahmed, F., Mahmud, S., Hatcher, J., \& Khan, S. M. (2006). Breast cancer risk factor knowledge among nurses in teaching hospitals of Karachi, Pakistan: a cross-sectional study. BMC nursing, 5(1), 6 . 
Aktin, C. (2001). Impact of public service messages "research evidence and effective strategies. Michigan University: Oregon State. Retrieved April 22, 2017 from http://message.net/research/index.html

Amin, S., Wahid, N., Wasim, B., \& Tabassum, S. (2011). Battling with breast cancer... addressing the issues. JPMA-Journal of the Pakistan Medical Association, 61(6), 597.

Amirali, Z., Edgar, K., Azim, Z. A., \& Sadruddin, S. (2014). Breast cancer in Pakistani females. i-Manager's Journal on Nursing, 4(2), 11.

Asif, H. M., Sultana, S., Akhtar, N., Rehman, J. U., \& Rehman, R. U. (2014). Prevalence, risk factors and disease knowledge of breast cancer in Pakistan. Asian Pac J Cancer Prev, 15(11), 4411-6.

Arendt, F., Northup, T., \& Camaj, L. (2019). Selective exposure and news media brands: Implicit and explicit attitudes as predictors of news choice. Media Psychology, 22(3), 526-543.

Avis, N. E., Crawford, S., \& Manuel, J. (2005). Quality of life among younger women with breast cancer. Journal of Clinical Oncology, 23(15), 3322-3330.

Banning, M., \& Tanzeem, T. (2013). Managing the illness experience of women with advanced breast cancer: hopes and fears of cancer-related insecurity. European journal of cancer care, 22(2), 253-260.

Glynn, R. W., Kelly, J. C., Coffey, N., Sweeney, K. J., \& Kerin, M. J. (2011). The effect of breast cancer awareness month on internet search activity-a comparison with awareness campaigns for lung and prostate cancer. BMC cancer, 11(1), 442.

Grow, J. M., \& Christopher, S. A. (2008). Breaking the silence surrounding hepatitis C by promoting self-efficacy: hepatitis C public service announcements. Qualitative Health Research, 18(10), 1401-1412.

Iftekhar, M. (2002) Impact of Public service Health Advertisements Campaign on PTV 1(Unpublished Master's thesis). University of the Punjab, Lahore.

Iftikhar, M., \& Mughal, M. K. (2017). Role of Public Service Educational Messages in Educating People about the Perceived Risk of Hepatitis. Journal of Mass Communication Department, Dept of Mass Communication, University of Karachi, 16.

Iftikhar, M., \& Islam, M. (2017). Construction of Female Identity In Pakistani Television Commercials (November, 2015-April, 2016): A Semiotic Analysis. Pakistan Journal of Gender Studies, 25.

Iftikhar, M., Raza, S. H., \& Khalid, S. (2018). Determining Association of Inter-Personal Communication of Families and Ledership Qualities of Women. Journal of $A d v$ Research in Dynamical \& Control Systems, 10 (04), 230-235.

İnci, B., Sancar, O., \& Bostanc1, S. H. (2017). Usage of health-themed public service announcements as a social marketing communication tool: A content analysis related to public service announcements in the Republic of Turkey, Ministry of Health's web site. Marketing and Branding Research, 4, 148-168. 
Keys, T. R., Morant, K. M., \& Stroman, C. A. (2009). Black youth's personal involvement in the HIV/AIDS issue: does the public service announcement still work?. Journal of health communication, 14(2), 189-202.

Klimes-Dougan, B., \& Lee, C. Y. S. (2010). Suicide prevention public service announcements: Perceptions of young adults. Crisis, 31 (5), 247-254. doi:10.1027/0227-5910/a000032

Masood, A., Masood, K., Hussain, M., Ali, W., Riaz, M., Alauddin, Z.,. \& Shahid, A. (2018). Thirty years cancer incidence data for Lahore, Pakistan: trends and patterns 19842014. Asian Pacific journal of cancer prevention: APJCP, 19(3), 709.

Pezzullo, P. C. (2003). Resisting "National Breast Cancer Awareness Month": The rhetoric of Counterpublics and their cultural performances. Quarterly Journal of Speech, 89(4), $345-365$.

Reichert, T., Heckler, S. E., \& Jackson, S. (2001). The effects of sexual social marketing related to public service announcements in the republic of Turkey, ministry of health's website. Marketing and Branding Research, 4,148-168.

Thackeray, R., Burton, S. H., Giraud-Carrier, C., Rollins, S., \& Draper, C. R. (2013). Using Twitter for breast cancer prevention: an analysis of breast cancer awareness month. BMC cancer, 13(1), 508.

Toncar, M., Reid, J. S., \& Anderson, C. E. (2007). Effective spokespersons in a PublicWalther, J. B., DeAndrea, D., Kim, J., \& Anthony, J. C. (2010). The influence of online:YouTube. Human Communication Research, 36, 469-492.

Wallack, L., Dorfman, L., Jernigan, D., \& Themba-Nixon, M. (1993). Media advocacy and public health: Power for prevention. Sage.

Zimmerman, R. K. (2007). HPV vaccine and its recommendations, 2007. Journal of Family Practice, 56(2), S1-S1. 